\title{
Emotional Abuse among Syrian Refugee Women in Jordan
}

\author{
Noha Al-Shdayfat ${ }^{1}$ \\ ${ }^{1}$ Noha Al-Shdayfat, Community and Mental Health Nursing Department, Al al-Bayt University, Mafraq, Jordan \\ Correspondence: Noha Al-Shdayfat, Community and Mental Health Nursing Department, Al al-Bayt University, \\ Mafraq, Jordan. Tel: 962-2-629-7000 Ext.2869; Fax: 962-2-629-7052 (Attn: Dr. Noha Al-Shdayfat). E-mail: \\ dr.nuhash@aabu.edu.jo
}

$\begin{array}{lc}\text { Received: December 4, } 2016 & \text { Accepted: January 8, } 2017 \quad \text { Online Published: January 31, } 2017 \\ \text { doi:10.5539/gjhs.v9n3p237 } & \text { URL: http://dx.doi.org/10.5539/gjhs.v9n3p237 }\end{array}$

\begin{abstract}
Background: Violence against women is a worldwide issue. Emotional abuse of women is the second most common form of abuse after physical abuse. Thus, this issue needs focus and attention especially among disadvantaged communities such as refugees.
\end{abstract}

Objective: This study aimed to investigate the prevalence of emotional abuse among Syrian refugee women in Jordan.

Methods: A descriptive cross-sectional study was conducted using a convenient sample of 182 Syrian refugee women residing in Mafraq Governorate. Participants were recruited from Maternal \& Child Health Centers (MCHC) across the governorate. A validated Arabic version of the NorVold Domestic Abuse Questionnaire (NORAQ) was used to collect data from the study participants.

Results: Participants' ages ranged from 19 to 55 years, (mean age \pm 30.2 ; $\mathrm{SD} \pm 8.9$ years). Forty four percent of the participants reported experiencing emotional abuse in the preceding year prior the evaluation. The lifetime prevalence of emotional abuse was $51.6 \%$. About $21.4 \%$ of married refugees surveyed reported emotional abuse from their husbands. Thirteen percent of the married participant reported being emotionally abused by their brothers. Twelve of the unmarried participants reported that the perpetrators were family members ( 4 fathers, 7 brothers, and 1 mother). Logistic regression model revealed that Syrian refugee women who are married, live within large families, reside in urban areas, and have lower educational levels are more likely to suffer emotional abuse. A significant association was found between exposure to emotional abuse and poor mental health, including depression, insomnia and feelings of anguish.

Conclusion: High prevalence rate of life time abuse was revealed by this study. Overall, findings suggest that improving socio-demographic circumstances (i e education) would reduce their vulnerability to emotional abuse. This study may guide both future research and current efforts to combat emotional violence amongst Syrian refugee women.

Keywords: emotional abuse, refugee, Syrian women, Jordan

\section{Background}

Since the Syrian crisis began, almost 1.5 million people have fled to neighboring countries such as Jordan (UNHCR, 2015). The majority of registered Syrian refugees in Jordan are young and unmarried females (Verme, 2015). Furthermore, approximately $85 \%$ of Syrian refugees in Jordan live outside of refugee camps - typically in informal settlements on the outskirts of major cities like Amman (UNHCR, 2015; Shteiwi, Walsh, \& Klassen, 2014). The 'non-camp' population tends to receive less attention from humanitarian agencies than the camp-dwelling populations (Shteiwi, Walsh, \& Klassen, 2014). The reason behind this might be that the humanitarian agencies supposed that the non-camp refugees live in better living circumstances.

Jordan is a middle-income country with limited resources stretched thin by the accommodation of large numbers of non-camp refugees (International Labor Organization, 2015). Initially, Jordan extended free healthcare services at public health facilities to refugees living outside of camps (Dlewati, 2015). It does seem unfortunate that this policy placed too much stress on the Jordanian health system, and as such, the government restricted the health care services available to refugees at these Ministry of Health-run facilities, leading to a major decrease in access 
to care in this population (UNHCR, WHO, Jordan University of Science and Technology, \& Ministry of Health, 2014).

Thus specifically it can be argued that existing health system structures in Jordan are not meeting the health needs of Syrian refugee women as well. The WHO has documented concerning levels of anemia in this population (WHO, 2015). It is also held that unmet need for mental health and gender-based violence (GBV) services may be particularly high in this population. Despite evidence of a mental health crisis amongst displaced Syrians, accessible mental health services are scarce in non-camp settings (Leigh, 2014; Coutts \& Fouad, 2013). The Minimum Initial Service Package (MISP) - the tool typically delivered in emergency situations to prevent and manage the consequences of GBV - has only been partially implemented in the city of Irbid (Steering Committee for Humanitarian Response, 1998; Krause, Williams, Onyango, Sami, Doedens, Giga, \& Tomczyk, 2015). MISP implementation is also incomplete in southern Jordan where there are no free GBV services available to the refugee population - despite a reported increase in GBV incidence (Alianza \& Solidaridad, 2015).

\subsection{Literature Review}

Violence against women is a worldwide public health problem that takes many forms - including psychological violence (WHO, 2002). Emotional abuse includes threats, coercion, and efforts to undermine a victim's self-worth or self-esteem (Follingstad et al., 2000). According to a WHO multi-country study of 24,000 women, one fifth to three quarters of women are psychologically abused by a partner in their lifetime (Garcia-Moreno, Jansen, Ellsberg, Heise, \& Watts, 2006).

Emotional abuse may have far worse negative psychological effects for its victims than other domestic abuse types (Gayle \& Robert, 2006). Emotional abuse can lead to feelings of worthlessness, and depression (Picó-Alfonso et al., 2006; O'Leary, 1999; Street et al., 2001; Coker et al., 2002) post-traumatic stress disorder, anxiety, and thoughts of suicide (Picó-Alfonso, García-Linares, Celda-Navarro, Blasco-Ros, Echeburua, \& Martinez, 2006). Emotional abuse is often accompanied by other types of violence, such as physical or sexual abuse (Sobkoviak, Yount, \& Halim, 2012; Krishnan, Hilbert, \& VanLeeuwen, 2001).

Few studies have described gender-based emotional abuse in the Eastern Mediterranean region (EMR). The existing literature focuses almost entirely on intimate partner violence (IPV), and gender-based abuse by male relatives other than the husband - which may be a significant contributor to the burden of emotional abuse in patriarchal societies like those in the EMR - has been widely neglected.

Based on the previous studies in the region; the available evidence suggests relatively high prevalence rates of intimate partner-perpetrated emotional abuse. A study conducted in Saudi Arabia found that the prevalence of emotional abuse among married women aged 16 to 60 years living in an urban area to be $32.8 \%$ (Tashkandi \& Rasheed, 2009). Likewise, 30\% of Jordanian women surveyed by Haddad, Shotar, Younger, Alzyoud, and Bouhaidar (2011) reported experiencing emotional abuse by their husbands, ex-husband and/or brothers.

Patriarchal theory has been the most frequently theoretical framework employed to understand domestic violence against women in the EMR. Violence against women phenomena was also addressed by the feminist theory which explained the parpetrators' actions to maintain control and power in the relationship with women. Male domination in economic matters and in decision-making, male beliefs about appropriate male behavior, male appraisal of stress, challenges and threats toward masculine norms, and power imbalance in relationships are strong predictors of domestic violence against women (Haj Yahya, 2005; Heise, 2011; Moore \& Stuart, 2005). Such male-dominated relationships are particularly prevalent among patriarchal societies in the EMR and thus may explain the fairly high rates of emotional abuse in the region (Bui \& Morash, 1999). It is worth noting that patriarchal relationship patterns may further inhibit disclosure of based emotional abuse when it occurs - making researchers more likely to under-report or under-estimate its prevalence (UN Women, 2013).

Syrian refugee women may be particularly at risk of experiencing abuse due to their refugee status. Refugee and immigrant women tend to have higher rates of emotional abuse, regardless of origin. Some $34.5 \%$ of South Asian immigrant women in the United States reported experiencing emotional abuse (Ahmad, Riaz, Barata, \& Stewart, 2004).

The Syrian refugee population has low socioeconomic status; and this may increase the vulnerability of the female refugees to be emotionally abused. An inter-agency assessment by UN Women of the risks faced by Syrian female refugees in Jordan reveals the poor socioeconomic characteristics of most Syrian refugee households in the country (2013). The majority of survey respondents - both men and women - did not continue their education after primary school. About $70 \%$ of households' heads had no paid jobs during the last month, despite the fact that more 
than half (52.7\%) of the respondents live in large families (between 5 and 8 members in size) (UN Women, 2013). The literature has documented a clear link between socio-economic factors and based emotional violence against women (Heise, 2011). That is, economical disadvantage of the family and unemployment of the husband are directly associated with emotional abuse of the wife.

Though there are some gender based violence (GBV) services available to Syrian women in Jordan, they are often inadequate in terms of confidentiality and specialization (UN Women, 2013). Displaced women may also be unaware of such services entirely as shown by the fact that the majority $(83 \%)$ of registered Syrian refugees surveyed in an inter-agency assessment were not fully aware of the services offered by UNHCR for GBV survivors (UN Women, 2013).

No studies to date have described the extent of emotional abuse amongst Syrian refugee women. Due to their refugee status, we expect a relatively high prevalence of emotional abuse in the female Syrian refugee population. Thus, the current study aims to determine the prevalence of emotional abuse and its predictors among Syrian refugee women in Jordan.

\section{Methodology}

2.1 Design

A descriptive, cross-sectional survey was conducted to describe the extent of emotional abuse among Syrian refugee women in Jordan.

The survey targeted Syrian refugee women aged 18 years or older who had been living in non-camp settings in Jordan for six months, or more, and were able to read and write Arabic.

A convenience sample of 182 Syrian refugee women was obtained. These participants were recruited from MCHCs in Mafraq governorate between March 1, 2014 and June 1, 2014. There are 47 MCHCs in Mafraq governorate; five MCHCs were purposefully recruited, three in Mafraq city and two from rural areas known to be populated by Syrian refugee families. The rule of thump ( $\mathrm{n}=30 \times$ number of predictors) (in regression analysis) was used to estimate the required sample size (Wilson, Voorhis, \& Morgan, 2007). There are 5 predictors in the current study. Thus, the sample size required was 150 participants. Yet, in order to reach at least 150 participants, some 280 Syrian refugee women who attended one of the five data collection sites were invited to participate; of those, 205 agreed to participate ( $73 \%$ response rate) and 182 were included. (23 participants who submitted partially-filled questionnaires were excluded.)

\subsection{Ethical Approval and Procedure}

Formal permission to conduct the research was obtained from AL al- Bayt University Institute Review Board (IRB) and from the ethical committee of the Jordanian Ministry of Health prior to data collection. All study participants had read a consent form prior to their participation in the study that described the study's aims and addressed ethical considerations (i.e. assurance of anonymous responses, explanation of the study purposes, voluntary participation and eligibility to withdraw from the study at any time). All subjects provided verbal consent prior to participation.

Questionnaires were distributed to participants in a private meeting room, and they were asked to return the questionnaires to the researcher once completed. MCHCs were chosen because the majority of Syrian refugees 84.5\% (CI: 83.0-87.5) sought health care at public sector facilities (i e MCHCs) (UNHCR, WHO, Johns Hopkins, Jordan University of Science and Technology, Ministry of Health, 2014). Though MCHCs is not the only agency that Syrian women can be encountered, it is the most convenient place in terms of privacy (the availability an empty room (i e the meeting room) where the participants who agreed to participate were allowed to use). In addition, most women who sought health care services from the MCHCs are expected to be not accompanied with a male relatives or husbands, which is not the case in other agencies.

\subsection{Instrument}

A validated Arabic version of the NorVold Domestic Abuse Questionnaire (NORAQ) was used to measure psychological abuse. This instrument had been previously translated into Arabic and validated by Haddad et al. (2011), who gave the researchers permission to use the tool for this study. Adapted versions of the NORAQ questionnaire are broadly used to estimate the prevalence of domestic abuse in populations of different socio-cultural contexts. The tool must be culturally validated, as it was originally developed to measure domestic violence among a very specific demographic population - white, western, middle-class women (Haddad, Shotar, Younger, Alzyoud, \& Bouhaidar, 2011). Construct validity was originally conducted by Swahnberg \& Wijma 
$(2003,2007)$. The NORAQ Arabic version revealed very good validity and reliability. The adapted NORAQ questionnaire was composed of five sections: past experience of emotional abuse, physical abuse, and sexual abuse, current experience of abuse (if any), and experience disclosing abuse to a primary care practitioner.

Table 1 shows the NORAQ questions about emotional abusive actions. The participants' responses on these questions were employed to classify the participants as severely, moderately or mildly abused.

Table 1. Detailed questions of emotional abusive acts

\begin{tabular}{ll}
\hline \multicolumn{1}{c}{ Emotional abuse } \\
\hline Mild abuse & $\begin{array}{l}\text { Have you experienced anybody systematically and for any longer period trying to } \\
\text { repress, degrade, or humiliate you? }\end{array}$ \\
Moderate abuse & $\begin{array}{l}\text { Have you experienced anybody and by threat and force trying to restrict your } \\
\text { contacts with others or totally control what you may or may not do ? }\end{array}$ \\
Severe abuse & $\begin{array}{l}\text { Have you experienced living in fear because somebody systematically and for any } \\
\text { long period has threaten you or somebody close to you? }\end{array}$ \\
\hline
\end{tabular}

In addition, the questionnaire captured demographic data such as age, education, participant occupation, husband occupation, income, and date of arrival in Jordan as well as the respondent's current physical and mental health.

Women who reported experiencing abuse were then asked to answer more detailed questions as part of the questionnaire including about their relationship to their abuser, when the incident happened; and if they experienced abuse after arriving to Jordan. Participants who reported experiencing any type of abuse were instructed to estimate their degree of current suffering, measured using a 10-point scale (with 0 equal to no suffering, and 10 equal to terrible suffering). The questionnaire ended with several questions asking whether the participant had reported their experience of abuse to the police, and if she feared becoming a victim of abuse in the future. Current suffering scores were scaled, and used to assess severity of the suffering.

\subsection{Data Entry and Management}

Data was sorted, coded and analysed using SPSS Version 19 for Windows. Descriptive statistics - including percentages, frequencies, and central tendency measures - were used to describe the demographic characteristics of the participants bivariate statistics were conducted to compare between demographic groups. $\chi^{2}$ tests were used for categorical variables, and t-tests for continuous variables. Tests with $\mathrm{p}$ values of less than 0.05 were considered significant. Multiple regressions were used to determine predictors of experiencing psychological abuse.

\section{Results}

\subsection{Sample Characteristics}

The sample composed of 182 Syrian refugee women. Most of the participants (143, 78.6\%) were married (Table 2). About two thirds of participants who are currently married, divorced or widowed $(\mathrm{N}=164) 67.1 \%$ reported (110 participants) that they were married before their eighteenth birthday. The participants' ages ranged from 19 to 55 years, with a mean age of 30.2 years. Most of the participants lived in relatively large households: $(n=129,70.9 \%)$ reported living with more than five family members. The majority of the participants ( $\mathrm{n}=161,88.5 \%$ ) belonged to low-income households ( $\leq 200$ Jordanian Dinar (JD) (= 142 US Dollars) a month). Almost half of the married participants $(\mathrm{N}=143)$, that is $\mathrm{n}=71(49.7 \%)$ reported that their husbands were unemployed. 
Table 2. Frequencies and percentage distributions of selected characteristics of the sample $(\mathrm{N}=182)$

\begin{tabular}{lll}
\hline Characteristic & Frequency & Percent \\
\hline Marital status & 143 & 78.6 \\
Married & 18 & 9.9 \\
Single & 15 & 8.2 \\
Widowed & 6 & 3.3 \\
Divorced & 133 & 73.1 \\
\hline Educational level attained & 42 & 23.1 \\
Primary & 5 & 2.7 \\
Secondary & 2 & 1.1 \\
College & & 36.8 \\
University & 67 & 63.2 \\
\hline Place of residence & 115 & \\
Rural & & 11.5 \\
Urban & 116 & \\
\hline Household Income & 21 & \\
$\leq 200$ JD & & \\
$>200$ JD & & \\
\hline
\end{tabular}

\subsection{Emotional Abuse Prevalence \& Associated Factors}

More than half of the participants $(\mathrm{n}=94,51.6 \%)$ reported a lifetime experience of emotional abuse (before and after refuge). Of these, more than one third (65 participants) reported mild emotional abuse- experiencing systematic and prolonged attempts at repressing, degrading, or humiliating them. Some 62 participants experienced moderate emotional abuse - being forced to limit their contacts with others or totally control what they may and may not do. About 37 participants experienced severe emotional abuse - constantly being threatened into limiting their relationships with others. The total number of the participants who reported the three types of the emotional abuse does not sum up to 94 because some participants reported experiencing more than one abusive action.

Almost half $(44.5 \%, \mathrm{n}=81)$ of respondents were exposed to emotional abuse during the last year. More than one fifth $(21.4 \%)$ of the married participants reported that their husbands were responsible for the abuse that they had exposed to, followed by brothers (13\%), and others (other family member) (12\%). Sixteen married participants reported being emotionally abused both by husband and a family member, such as their brother, father, and mother. Some 43 participants (23\%) reported being physically abused in addition to experiencing emotional abuse.

Analysis of frequency $\left(\chi^{2}\right)$ tests revealed significant associations between experience of emotional abuse and several mental health outcome variables, including depression $\left(\chi^{2}=22.2, p=0.001\right)$ insomnia $\left(\chi^{2}=25.7, p=0\right.$. $001)$ and feelings of anguish $\left(\chi^{2}=34.5, p=0.001\right)$. However, those participants who reported higher scores on the currently suffering scale were more likely to seek psychological counseling $(t-t e s t=-2.02, p=0.05)$.

Certain demographic groups within the study sample were significantly associated with emotional abuse. Married women were more likely to experience emotional abuse than unmarried women (single, divorced and widowed) $\left(\chi^{2}=9.2, p=0.002\right)$. Women living in large families (more than five members) were more likely to report emotional abuse than women living in smaller families (five members or less) $\left(\chi^{2}=7.8, \mathrm{p}=0.005\right.$ ). Less educated women were more likely to be emotionally abused $\left(\chi^{2}=10.1, \mathrm{p}=0.001\right)$. Women living in urban areas were more likely to experience emotional abuse compared to those living in rural areas $\left(\chi^{2}=5.6, \mathrm{p}=0.01\right)$. Household income $(\leq 200 \mathrm{JD}$ compared to $>200 \mathrm{JD})(1 \mathrm{JD}=1.41$ US\$) and participants' age ( $\leq 25$ years compared to the older participants; 
aged $>25$ years) were not significantly associated with experience of emotional abuse.

Certain demographic factors were associated with having a less severe suffering score. Unmarried women, educated (attended secondary school or more), women living in rural areas, and those living with five or lower household members were less likely to report a high suffering score (see Table 3 ). Household income ( $\leq 200 \mathrm{JD}$, and $>200 \mathrm{JD}$ ), husbands' employment status, participants' age (aged 25 years or less compared to the older participants), marriage age (women who got married at or before 20 years old and after their 20th birthday) did not account for any significant differences in mean suffering score.

Table 3. The associations between the psychological suffering and the participants' marital status, educational level, family size, and place of residence $(\mathrm{N}=81)$

\begin{tabular}{lccllll}
\hline & $\begin{array}{c}\text { T-test } \\
\text { value }\end{array}$ & $\begin{array}{c}\text { Degree of } \\
\text { freedom }\end{array}$ & P Value & CI & Mean & Mean \\
\hline Marital status & 2.5 & 80 & 0.01 & $0.5-4.3$ & 7.4 & Unmarried \\
& 2.3 & 80 & 0.02 & $0.3-3.5$ & 5.5 & 5.0 \\
\hline Educational level & & & & & $\leq$ five members & $>$ five members \\
& & & 0.00 & $-4.2-1.5$ & 4.7 & 7.6 \\
\hline Family size & -4.2 & 80 & & & Rural & Urban \\
\hline Place of residence & & & 0.00 & $0.6-2.8$ & 6.0 & 7.7 \\
\hline
\end{tabular}

The findings also revealed that only $6.4 \%$ of the emotionally abused women had told a health care professional about it. Almost half (45.7\%) had disclosed the abuse to a friend, and more than one fifth (22.3\%) to a relative, while none of the participants reported the abuse to the police office (Table 4).

Table 4. Patterns of help seeking and emotional abuse experience disclosing by the emotionally abused participants. $(\mathrm{N}=94)$

\begin{tabular}{lcc}
\hline Characteristic & Number & Percentage \\
\hline $\begin{array}{l}\text { Sought care or counseling in regard to } \\
\text { abuse from a nurse }\end{array}$ & 6 & $6.4 \%$ \\
\hline $\begin{array}{l}\text { Sought care or counseling } \\
\text { in regard to abuse from a physician }\end{array}$ & 3 & $3.2 \%$ \\
\hline $\begin{array}{l}\text { Reporting their abuse status to a } \\
\text { non-health care professionals }\end{array}$ & & \\
Relatives & 21 & \\
Friends & 43 & $22.3 \%$ \\
Police & 0 & $45.7 \%$ \\
\hline
\end{tabular}


A regression analysis was conducted to determine the extent to which emotional abuse suffer score could be predicted by the participants' demographic variables (marital status, educational level, family size, and place of residence). Using the enter method, a significant regression model was determined: $F=10.9, p<0.000$. The model explains 36.3 percent of the variance (adjusted $\mathrm{R}^{2}=0.363$ ) in the participants' suffering score. The correlation matrix between the independent variables showed no evidence of multi-colinearity (VIF was less than 1.06). The strongest predictor of the emotional suffering score is family size (Beta $=0.32$ ) followed by place of living, educational level and marital status with Beta values $-0.27,-0.26$ and -0.24 respectively. Marital status, educational level, family size, and place of residence contributed to the variance in the emotional suffering scale score indicating that women who were unmarried, educated, live in small family size and in rural area were less likely to report high scores in the emotional suffering scale.

\section{Discussion}

This is the first study to assess the extent of emotional abuse among Syrian refugee women in Jordan - a population that is triply-susceptible to emotional violence due to the compounded risks associated with their cultural norms, gender and displacement.

We reported a past-year prevalence of emotional abuse within this population of $44.5 \%$, and a lifetime prevalence of emotional abuse in this population of 51.6\%. Notably, this figure for lifetime prevalence exceeds that of similar studies carried out in the region - possibly due to the exacerbating effects of conflict and displacement in this population (Tashkandi \& Rasheed, 2009). For example, the prevalence rates in the region are $30 \%$, and $32.8 \%$ in Jordan and Saudi Arabia respectively (Tashkandi \& Rasheed, 2009; Haddad, Shotar, Younger, Alzyoud, \& Bouhaidar, 2011). However, in congruent with the current study findings; high prevalence rates of emotional abuse was estimated in middle eastern countries such as Iran with emotional violence prevalence equal to $44.4 \%$ (Jahromi, Jamali , Koshkaki \& Javadpour, 2004),. However, the prevalence rate of women emotional abuse in some developing countries is as low as $12.1 \%$ in USA (Coker, Davis, Arias, Desai, Sanderson, Brandt, \& Smith, 2002). Surprisingly, the prevalence of emotional violence in some developed countries such as Japan is estimated to be $60 \%$ Weingourt, Maruyama, Sawada, \& Yoshino, 2001). Nevertheless, the conflict in the findings might be related to methodological and/or instrumental variations.

We also report a coexistence of emotional abuse and physical abuse of $23 \%$, which agrees with the literature (Coker, Davis, Arias, Desai, Sanderson, Brandt, \& Smith,_2002; Haddad et al., 2011; Btoush \& Haj-Yahia, 2008; Badayneh, 2004). Our findings agree with similar studies, which have revealed an association between demographic characteristics and emotional abuse status, such as the family size (Flake, 2005). In addition, in consistent with the previous literature, the current study findings revealed that women with secondary education and higher attainment less likely to experience emotional abuse (Koenig, Lutalo, Zhoa, Nalugoda, Wabwire-Mangen, Kiwanuka, \& Gray, 2003).

Most married participants in the current study (67.1\%) were married before their twentieth birthday. It is worth noting that early marriage is generally considered to be a form of gender-based violence itself - as boys and girls aged less than 18 are considered ineligible to give valid consent (UN Women, 2013). Furthermore, feminist scholars highlighted the adverse consequences of adolescent girls' marriage on their education as well as increasing their vulnerability to domestic abuse. A trend of early marriage age among Syrian girls may account for the relatively high numbers of study participants in the 19-to-35 age range, though this can also be explained by the fact that participants were recruited from maternal and child health clinics, where most of the Syrian refugee women of reproductive age utilize maternal and child health care services.

Women who are displaced from their own countries have low access to health, social and security services. Accordingly, in this study, only 9 emotionally abused participants $(0.09 \%, \mathrm{~N}=94)$ reported disclosing their experience of emotional abuse to their health care provider (Table 4). This finding might be explained by cultural norms that considered domestic violence as a private family matter and should not be discussed with the outsiders.

\section{Limitations}

This study has two major limitations: first, it utilizes a relatively small sample size. Additionally, the study sample only includes Syrian female refugees living outside of refugee camps - women living in camps were not approached, and thus, our findings cannot be generalized to the entire female Syrian refugee population. However, almost all refugees in Jordan live in severely disadvantaged economical, social and political circumstances and it is 
possible that the demographic trends reported here may occur in the in-camp population as well. Also, the illiterate women were not included in the sample because the instrument is self administered; thus, only women who can read and write were able to participate. Therefore, findings of the study cannot be generalized on illiterate women.

\section{Recommendations}

High prevalence rate of emotional abuse among Syrian refugee women has been revealed by the current study findings. Accordingly, there is an urgent need to intervene with such dilemma. This intervention is crucial given the fact that emotionally abused Syrian women rarely reported their experiences with or seek help from health professionals. Thus, primary prevention of this violence should start by training the health professionals to encourage their clients to disclose their domestic violence experiences.

Mental health counseling is also recommended for this population especially because a significant association was found between being emotionally abuse and experiencing negative mental consequences such as depression, insomnia and anguish feelings. In addition efforts should aim to empower Syrian refugee women by improving their socio-demographic conditions such as education.

Further research is needed to investigate what types of training may help health professionals to provide better services to Syrian refugee women. Thus, we suggest a qualitative study to explore health professionals' attitudes towards Syrian women who seek help for domestic violence issues. It may also be helpful to study health professionals' attitudes regarding effective measures that may encourage women, especially those live in a disadvantaged situation like Syrian refugees, to seek help in abuse matters. In addition, further qualitative research on the victims' opinions of on how to curb abuse is recommended. Such a sound and complete assessment will aid policy-makers in designing public health programs to effectively meet the needs of this population.

\section{Acknowledgements}

I would like to thank all the refugee women who participated in the current study. Thanks extended to Dr Linda G Haddad and Dr Sukaina Alzyoud for their support during the early phase of the study. Without the help of the research assistants Miss Yasmeen Abusummaqah and Rana Shdaifat during the data collection phase this work would not have been possible.

\section{Competing Interests Statement}

The author confirms that this article content has no conflict of interest.

\section{References}

Ahmad, F., Riaz S, Barata, P., \& Stewart, D. E. (2004). Patriarchal Beliefs and Perceptions of Abuse among South Asian Immigrant Women. Violence Against Women, 10(3), 262-282. https://doi.org/10.1177/1077801203256000

AL-Badayneh, D. (2004). The national scope for protection of Jordanian families from family violence. Amman, Jordan: National Council for Family Affairs

Bott, S., Guedes, A., Goodwin, M., \& Mendoza, J. (2012). Violence against women in Latin America and the Caribbean: a comparative analysis of population-based data from 12 countries. Washington, DC: Pan American Health Organization Convention Relating to the Status of Refugees, 28 July 1951, 189 U.N.T.S. 150.

Btoush, R., \& Haj-Yahia, M. M. (2008). Attitudes of Jordanian society about wife abuse. Journal of Interpersonal Violence, 23(11), 1531-1554. https://doi.org/10.1177/0886260508314313

Bui, H. N., \& Morash, M. (1999). Domestic Violence in the Vietnamese Immigrant Community an Exploratory Study. Violence Against Women, Sage Journals, 5(7), 769-795. https://doi.org/10.1177/10778019922181473

Coker, A. L., Davis, K. E., Arias, I., Desai, S., Sanderson, M., Brandt, H. M., \& Smith, P. H. (2002). Physical and mental health effects of intimate partner violence for men and women. 2002. Am J Prev Med., 23(4), 260-268. https://doi.org/10.1016/S0749-3797(02)00514-7

Coker, A. L., Smith, P. H., Thompson, M. P., McKeown, R. E., Bethea, L., \& Davis, K. E. (2002). Social support protects against the negative effects of partner violence on mental health. Journal of Women's Health \& 
Gender-Based Medicine, 11(5), 465-76. https://doi.org/10.1089/15246090260137644

Counseling Center, University of Illinois Urbana-Champaign. (2013). Emotional abuse. $\mathrm{http} / / /$ counselingcenter.illinois.edu/

Coutts, A., \& Fouad, F. M. (2013). Response to Syria's health crisis-poor and uncoordinated. The Lancet, 381(9885), 2242-2243. https://doi.org/10.1016/S0140-6736(13)61421-X

Dlewati, H. (2015). Syrian Refugees Face a Medical Crisis in Jordan. Fulbright National Geographic Stories. Retrieved from http://voices.nationalgeographic.com/2015/12/17/syrian-medical-situation-in-jordan-illegaldoctors/

Flake, D. F. (2005). Individual, family, and community risk markers for domestic violence in Peru. Violence against Women, 11(3), 353-373. https://doi.org/10.1177/1077801204272129

Follingstad, D. R. Rutledge, L. L., Berg, B. J., Hause, E. S., \& Poleck, D. S. (1990). The Role of Emotional Abuse in Physically Abusive Relationships. Journal of Family Violence, 5(2), 107-120. https://doi.org/10.1007/BF00978514

Garcia-Moreno, C., Jansen, H., Ellsberg, M., Heise, L., \& Watts, C. (2006). Prevalence of intimate partner violence: Findings from the WHO multi-country study on women's health and domestic violence. Lancet, 368, 1260-1269. https://doi.org/10.1016/S0140-6736(06)69523-8

Gayle L. R., \& Robert, E. D. (2006). The Effects of Forgiveness Therapy on Depression, Anxiety, and Posttraumatic Stress for Women After Spousal Emotional Abuse. Journal of Consulting and Clinical Psychology, 74(5), 920-929. https://doi.org/10.1037/0022-006X.74.5.920

Haddad, L. G., Shotar, A., Younger, J. B., Alzyoud, S., \& Bouhaidar, C. M. (2011). Screening for domestic violence in Jordan: validation of an Arabic version of a domestic violence against women questionnaire. International Journal of Womens' Health, 3, 79-86. https://doi.org/10.2147/IJWH.S17135

Haj-Yahia, M. M., \& Eldeson, J. L. (2005). Can people's patriarchal ideology predict their beliefs about wife abuse? The case of Jordanian men. Journal of Community Psychology, 33(5), 545-567. https://doi.org/10.1002/jcop.20068

Heise L. L. (2011). What works to prevent partner violence? An evidence overview. London: Centre for Gender Violence and Health, London School of Hygiene and Tropical Medicine, Retrieved from http://strive.lshtm.ac.uk/system/files/attachments/What\%20works\%20to\%20prevent\%20partner\%20violenc e.pdf.

International Labor Organization (ILO). (2015). Access to work for Syrian refugees in Jordan: A discussion paper on labour and refugee laws and policies. file://C:/Users/Acer\%20Veriton\%20M2631/Downloads/ ILOAccesstoWorkofSyrianRefugeesinJordan.pdf

Jahromi, M. K, Jamali, S., Koshkaki, A. R., \& Javadpour, S. (2016). Prevalence and Risk Factors of Domestic Violence Against. Women by Their Husbands in Iran. Glob J Health Sci, 8(5), 175-183. https://doi.org/10.5539/gjhs.v8n5p175

Koenig, M. A., Lutalo, T., Zhoa, F., Nalugoda, F., Wabwire-Mangen, F., Kiwanuka, N., \& Gray, R. (2003). Domestic violence in rural Uganda: Evidence from a communitybased study. Bulletin of the World Health Organization, 81, 53-60.

Krause, S., Williams, H., Onyango, M. A., Sami, S., Doedens, W., Giga, N., \& Tomczyk, B. (2015). Reproductive health services for Syrian refugees in Zaatri Camp and Irbid City, Hashemite Kingdom of Jordan: An evaluation of the Minimum Initial Services Package. Conflict and Health, 9(Suppl 1), S4. https://doi.org/10.1186/1752-1505-9-S1-S4

Krishnan, S., Hilbert, J. C., \& VanLeeuwen, D. (2001). Domestic Violence and Help - Seeking Behaviors among Rural Women: Results from a Shelter-Based Study. Family \& Community Health, 24(1), 28-38. https://doi.org/10.1097/00003727-200104000-00006

Leigh, K. (2014). Syria's Mental Health Crisis. The New York Times. http://mobile. nytimes. 
com/blogs/kristof/2014/08/01/syrias-mental-health-crisis.

Moore, Todd. M., \& Stuart, G. L. (2005). A Review of the Literature on Masculinity and Partner Violence. Psychology of Men \& Masculinity, 6(1), 46-61. https://doi.org/10.1037/1524-9220.6.1.46

O'Leary, \& Daniel, K. (1999). Psychological Abuse: A Variable Deserving Critical Attention in Domestic Violence. Violence and Victims, 14(1), 3-23(21)

Picó-Alfonso, M. A., García-Linares, M. I., Celda-Navarro, N., Blasco-Ros, C., Echeburua, E., \& Martinez, M. (2006). The impact of physical, psychological, and sexual intimate male partner violence on women's mental health: depressive symptoms, posttraumatic stress disorder, state anxiety, and suicide. Journal of Women's Health, 15, 599-611. https://doi.org/10.1089/jwh.2006.15.599

Shteiwi, M., Walsh, J., \& Klassen, C. (2014). Coping With The Crisis; A Review of the Response to Syrian Refugees in Jordan. Center for Strategic Studies, Amman, Jordan. http://www.jcss.org/Photos/635520970736179906.pdf

Sobkoviak, R. M., Yount, K. M., \& Halim, N. (2012). Domestic violence and child nutrition in Liberia. Social Science \& Medicine, 74(2), 103-111. https://doi.org/10.1016/j.socscimed.2011.10.024

Steering Committee for Humanitarian Response. (1998). The Sphere Project: Humanitarian Charter and Minimum Standards Disaster Response. Retrieved from http://www.spherehandbook.org/

Street, A. E., \& Arias, I. (2001). Psychological abuse and posttraumatic stress disorder in battered women: examining the roles of shame and guilt. Violence and Victims, 16, 65-78.

Swahnberg, K., \& Wijma, B. (2003). The NorVold Abuse Questionnaire: validation of new measures of emotional, physical, and sexual abuse, and abuse in the health care system among women. Eur J Public Health, 13, 361-366.

Swahnberg, K., \& Wijma, B. (2007). Validation of the Abuse Screening Inventory (ASI). Scand J Public Health, 35, 330-334. https://doi.org/10.1080/14034940601040759

Tashkandi, A. A., \& Rasheed, P. (2009). Wife abuse: a hidden problem. A study among Saudi women attending PHC centers. East Mediterranean Health Journal, 15(5), 1242-1253.

UN Women. (2013). (Report). Gender based violence and child protection among Syrian refugees in Jordan; Interagency assessment. Queen Zein Al-Sharaf Institute for Development (ZENID). http://www.unwomen.org/ /media/headquarters/attachments/sections/library/publications/2013/7/report-we b\%20pdf.pdf

UNHCR (United Nations High Commissioner for Refugees). (2015). Health access and utilization survey among non-camp refugees in Jordan.

UNHCR, WHO, Johns Hopkins University, Jordan University of Science and Technology, Jordanian Ministry of Health. (2014). Syrian Refugee Health Access Survey in Jordan.

Verme, P. (2015). The Welfare of Syrian Refugees: Evidence from Lebanon and Jordan. World Bank and the UN Refugee Agency (UNHCR). https://doi.org/10.1596/978-1-4648-0770-1

Weingourt, R., Maruyama, T., Sawada, I., \& Yoshino, J. (2001). Domestic violence and women's mental health in Japan. Inter Nurs Rev., 48, 102-8. https://doi.org/10.1046/j.1466-7657.2001.00059.x

WHO (World Health Organization), UNFPA (United Nations Population Fund) and Junta de Andalucia. (2009) Granada Consensus on Sexual and Reproductive Health in Protracted Crises and Recovery. WHO, Geneva.

WHO. (2015). Syria Crisis: Country brief and funding request. WHO, Geneva. http://reliefweb.int/sites/reliefweb.int/files/resources/WHO\%20Jordan\%20January\%20to\%20June\%20Don or\%20update.pdf.

Wilson, C. R., Voorhis, W. V., \& Morgan, B. L. (2007). Understanding Power and Rules of Thumb for Determining Sample Sizes. Tutorials in Quantitative Methods for Psychology, 3(2), 43-50. https://doi.org/10.20982/tqmp.03.2.p043 


\section{Copyrights}

Copyright for this article is retained by the author, with first publication rights granted to the journal.

This is an open-access article distributed under the terms and conditions of the Creative Commons Attribution license (http://creativecommons.org/licenses/by/4.0/). 